Rev Chil Salud Pública 2012;

Vol 16 (1): $58-60$

Entrevista

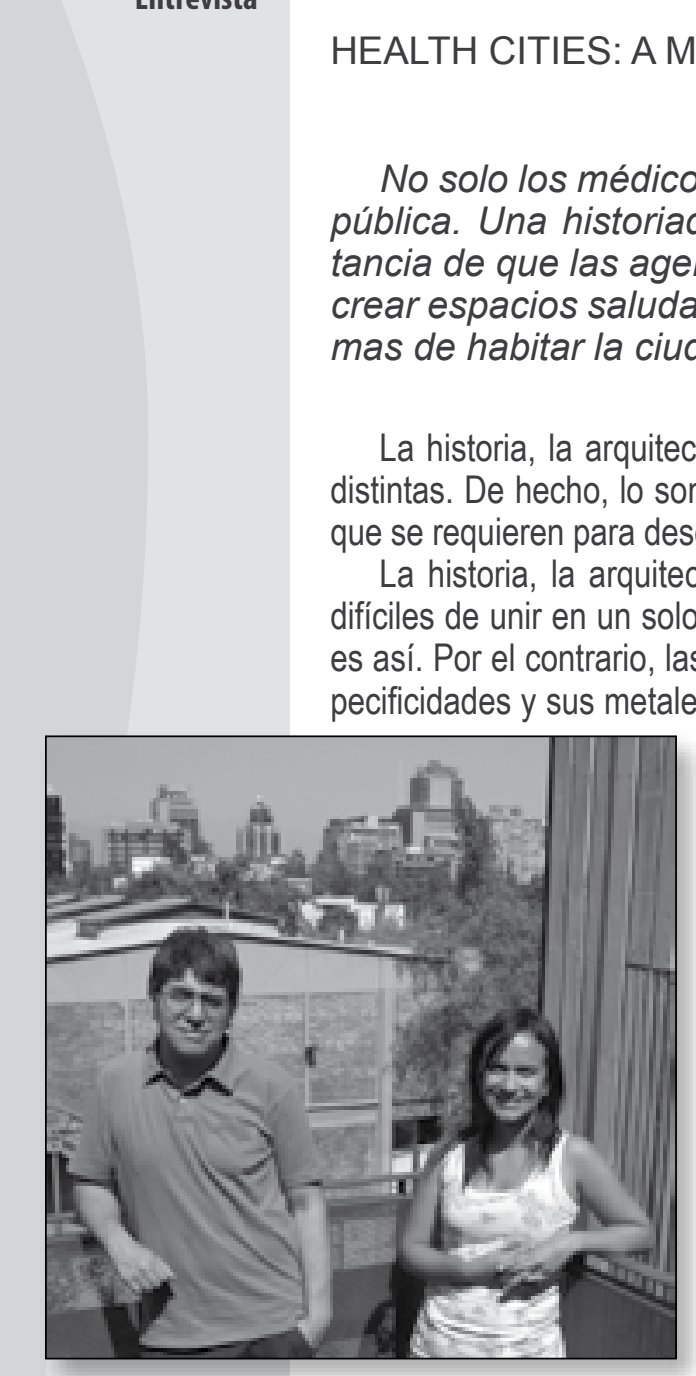

\title{
Ciudades saludables: un desafío multisectorial
}

\author{
HEALTH CITIES: A MULTISECTORAL CHALLENGE
}

\begin{abstract}
No solo los médicos tienen algo que decir en materia de salud pública. Una historiadora y un arquitecto ahondan en la imporgendas de diferentes sectores converjan para crear espacios saludables, capaces de interpretar las nuevas formas de habitar la ciudad.
\end{abstract}

La historia, la arquitectura y la salud pública parecen ser disciplinas muy distintas. De hecho, lo son, y tanto las competencias como los conocimientos ue se requieren para desenvolverse en cada una de ellas son muy diferentes.

La historia, la arquitectura y la salud pública parecen también ser áreas difíciles de unir en un solo proyecto o con un mismo objetivo. $Y$ eso sí que no es así. Por el contrario, las tres y varias más pueden converger desde sus especificidades y sus metalenguajes, desde su teoría y su praxis, para contribuir a la sociedad en algo tan básico y a la vez tan complejo como es el mejoramiento de la salud y las condiciones de vida de la población.

Así lo han entendido la historiadora de la Universidad Católica Macarena Ibarra y el arquitecto de la Universidad de Chile y profesor de la Universidad Técnica Federico Santa María, Rodrigo Mora, autores del artículo "Habitar la escuela: el problema de la infraestructura y su relación con las enfermedades escolares en Chile", publicado en 2011 en la revista INVI. Estos profesionales se ocuparon particularmente del entorno escolar, pero, para llegar a él, indagaron en el rol entre ciudad y salud en distintas etapas de la historia de Chile. El estudio aborda la epidemia de viruela que azotó con fuerza al país hace más de cien años y la obesidad, principal problema nutricional de nuestros días.

Macarena Ibarra, académica del Instituto de Estudios Urbanos y Territoriales de la PUC, cuenta que en los espacios escolares construidos en Chile a mediados del siglo XIX se recogían las normas y estándares de higiene que se discutían en Europa, donde ya se vivía una fuerte corriente higienista. "Pero a principios del siglo XX se produjo una transformación cultural cuando el médico entra a la ciudad. Después entra el maestro de escuela a generar presión sobre

YURI CARVAJAL ${ }^{(1)} y$ DANIELA ARANEDA ${ }^{(1)}$

(1)Escuela de Salud Pública. Facultad de Medicina. Universidad de Chile. Independencia 939. Santiago. Chile. ycarvajal@med.uchile.cl las condiciones de higiene ", añade. Más tarde se incorporan el arquitecto, el urbanista y otros que comprenden de manera más integral esta relación entre el hábitat y la salud de las personas.

- ¿Qué medidas se tomaban en ese entonces?

- Como ya existía la percepción de que ciertos espacios que eran habitados por largas jornadas -como la escuela- favorecían la aparición o el contagio 
de determinadas patologías, se llegó incluso a plantear que reduciendo la jornada escolar disminuiría el riesgo de que los niños contrajeran enfermedades infecciosas. Otra preocupación que se mantuvo por largo tiempo fue la de sanitizar las rutas de acceso a los colegios.

En 1909 el arquitecto Ricardo Larraín Bravo publicó su libro "La higiene aplicada a las construcciones". Su obra aparece como un referente para la construcción de escuelas, hospitales, cárceles y otros edificios, en cuanto consideraba aspectos como la cantidad y tamaño de las ventanas, la iluminación, la ventilación y otros, de los cuales hasta esa época no se hablaba.

- ¿Cómo evolucionó la mirada al tema durante el resto del siglo XX?

-Poco a poco, la higiene se va convirtiendo en un tema de ciudad y esa relación se va haciendo más compleja, involucrando a distintos actores. Se agrega el vínculo entre espacio y comportamiento; es decir, ciertas condiciones espaciales facilitan o dificultan la adopción de conductas que, a su vez, son beneficiosas o perjudiciales para la salud, todo esto influido también por el individuo y la cultura.

Por otra parte, a diferencia del siglo pasado, cuando eran las enfermedades infecciosas las que causaban estragos en la población escolar y adulta, hoy en día las enfermedades no transmisibles, ligadas precisamente a la conducta, constituyen el principal problema de salud pública, dentro de ellas, la obesidad es la más importante, tanto por su incidencia a nivel global como por su rápido crecimiento en la población juvenil y por ser, en gran medida, generadora de otras patologías.

\section{Hacia la ciudad saludable}

Rodrigo Mora trabaja en el Departamento de Arquitectura de la Universidad Técnica Federico Santa María. Se ha dedicado a estudiar temas como las ciudades saludables y, en el último tiempo, la obesidad en los espacios escolares. En el camino, vio que hay preguntas comunes a ambos y respuestas que tienen que ver con la naturaleza de las ciudades. "Hay una convergencia de agendas: sectores como transporte, energía, salud, vivienda, tienen que conformar una sola, apuntando a la sustentabilidad urbana", precisa, agregando que así han de surgir las respuestas a un problema de salud pública.

-En la práctica, ¿se ha producido esa convergencia?

-Mirado así, el tema no estaba siendo abor-

\section{Repensar la escuela}

A la hora de hablar del espacio escolar, Macarena Ibarra y Rodrigo Mora coinciden en que este, como parte de la ciudad, debe adaptarse a las nuevas formas de habitar. "Se debe reconocer la forma en que la escuela es habitada hoy, a principios del siglo XXI, desde sus cualidades, desafíos y formas de enseñar, para plantear una forma de habitarla de acuerdo a ello", señala la historiadora de la PUC. Agrega que repensar la escuela implica reconocer las necesidades específicas de ese espacio y de sus usuarios, que son diferentes a las de una vivienda, un hospital o una oficina, y concebirla desde su funcionalidad.

Rodrigo Mora acota que varias intervenciones exitosas en países desarrollados se relacionan con el aumento de las horas de actividad física, la intensificación de esta o la generación de recreos activos. Sostiene que también hay iniciativas de promoción de alimentación saludable y educación de padres y escolares respecto de los beneficios de mantener hábitos de vida que prevengan enfermedades. Desde el punto de vista espacial, facilitar el desplazamiento de alumnos y padres a pie o en bicicleta a través de rutas seguras es otra medida que ha dado resultados en otros países. "Pero lo importante es mantener el diálogo entre la profesión médica, los diseñadores de espacios y otras disciplinas, resguardando las cualidades pedagógicas que ese espacio debe contener", precisa el experto. 
dado en las agendas chilenas. En las investigaciones de los años ' 80 recién se habla de obesidad, en los '90 ya es una preocupación y en el siglo XXI ya se ven acciones, como el fomento a la actividad física y la Estrategia Global contra la Obesidad (EGO). Pero esta todavía no tiene una bajada a la ciudad; es patente la ausencia de contenidos urbanos y arquitectónicos en las recomendaciones generadas por este documento.

Chile todavía no logra incorporar arquitectos, urbanistas, gente que está ocupada del ambiente físico. Ello sí ha ocurrido a nivel de gobiernos locales, que han sido más atentos y eficientes en captar este cambio de mentalidad que las autoridades centrales. A mi juicio, esto se debe a que el debate ha sido liderado por el cuerpo médico; es decir, el problema es mirado sólo desde la perspectiva clínica. De hecho, hicimos revisión de artículos sobre obesidad y en ninguno aparece un arquitecto, geógrafo o urbanista. Entonces, así no es raro que estas variables no estén presentes.

- ¿Hacia dónde deberían apuntar las intervenciones?

-Las que hemos visto son más bien informativas, de cambio curricular, pero está probado que estas no son tan efectivas como las que contemplan la creación de espacios que induzcan al comportamiento saludable. Las ciclovías, por ejemplo, si son eficientes la gente las va a usar, y se ha visto en Santiago; lo mismo con los parques o las máquinas de ejercicios en las plazas.

- ¿Podemos hablar, entonces, de una relación entre los objetos y la salud/enfermedad?

-Las variables espaciales no son determinantes, pero sí intervinientes en el comportamiento. El espacio importa y tiene efectos, así como las características personales, culturales o educacionales, que tienen que ver con la actitud frente al deporte, la alimentación, etc. En ese contexto, la existencia de lugares de recreación también favorece la conducta y hay que considerarlo. No es que el espacio vaya necesariamente a producir el comportamiento, pero va a influir.
Otro dato que ilustra el vínculo entre el espacio físico y la salud: en Estados Unidos, un estudio reveló que los pacientes hospitalizados en una pieza con vista a un jardín o un parque tienen una mejor evolución y menor tiempo de estadía que quienes sólo pueden mirar una pared.

- Desde esa perspectiva, ¿cómo debería ser la ciudad saludable?

- Lo primero es entender que hoy la ciudad se habita de una forma diferente a hace cien años, y las políticas deben incorporar esa tendencia. Habitar la ciudad implica morar, desarrollarse en ella, lo mismo en la escuela. Además, las cosas deben hacerse a la escala de las personas que viven en la ciudad.

La ciudad saludable tiene efectos que ayudan a la habitabilidad urbana. Esto quiere decir que, para que la gente use los espacios públicos, estos además tienen que ser seguros, con lo cual se está atacando otro problema de las ciudades. Un buen ejemplo es el parque construido en el bandejón central de la avenida Pocuro (comuna de Providencia, Santiago); es una estructura bien cuidada, de siete metros de ancho, que funciona como un gran gimnasio al aire libre, con una tasa de ocupación mucho mayor que la de los gimnasios cerrados y con gran presencia de mujeres, incluso en las noches, porque está bien iluminado y es seguro. En sectores más populares también hay experiencias exitosas de este tipo, pero debería haber más, porque estos espacios además tienen un efecto social, la gente va acompañada, se fortalecen las redes y se obtienen beneficios que van mucho más allá de una máquina de ejercicios.

Los huertos urbanos, que existen en otros países y que hubo en Chile en los años ' 60 , son otra iniciativa que estimula a la gente a trabajar por su entorno en actividades como reciclaje o compostaje. De esta manera, todos hacen un aporte a la ciudad, a su barrio, a su salud y a la sostenibilidad urbana.

Para conseguir los objetivos que se plantean al hablar de ciudad saludable, no se puede olvidar la mirada multidisciplinaria, que debe ir desde el diagnóstico de la situación actual hasta la implementación de las intervenciones. Ese es un gran desafío para las políticas públicas. 